\title{
„SMRT JE KALEŽ, A ČOVJEK KUŠAČ“: SMRT U STARIJOJ ARAPSKOJ POEZIJI
}

\section{Edin Muftić}

UDK: 821.411.21-1:612.013

Stručni članak

Sažetak: Smrt je trajna inspiracija pjesnika. Autor analizira odnos prema smrti arapskih predislamskih i islamskih pjesnika. Arapski predislamski pjesnici ostavili su neke od najpotresnijih stihova o prolaznosti života i neminovnosti smrti. Iako iz sačuvanog korpusa poezije ne možemo izvući jasne zaključke o onosvjetskim idejama predislamskih Arabljana, pesimistički svjetonazor prožima njihove stihove. Iz beznadnosti javlja se i specifičan hedonizam te poziv na uživanje u životu koji će prerano završiti. Islam je ovo promijenio. Musliman više nije dvojio oko postojanja onostranog. On je siguran da je smrt tek prijelaz na drugu stranu, gdje ga čeka ili nagrada kojoj se nada ili kazna od koje strahuje, pa smrt ne doživljava kao gorki kraj. Ovo je najjasnije u poeziji najvećeg arapskog pjesnika Mutanabbija koji, oplakujući voljene, smrt izaziva na dvoboj.

Ključne riječi: islam, smrt, predislamska poezija, muallake, Mutanabbi

Tko ne umre od mača, umre od čega drugog, mnoštvo je uzroka, ali smrt je samo jedna. Ibn Nubata as-Sa'di (938. - 1015.)

bn Nubata as-Sa' di bio je dvorski pjesnik Sejfud-Davla (945. - 967.), vladara hamdanidske dinastije. Junačka smrt od mača nije mu bila strana. Sjajni ratnici i vješti pjesnici, vladari alepske grane dinastije tijekom druge polovine 10. stoljeća veći su dio vladavine provodili u bezbrojnim čarkama na granici s Bizantom. Suočen s istočnom ekspanzijom Bizanta u vrijeme energičnih vladara makedonske dinastije (Roman II. i Nikefor II. Foka), Sejfud-Davla je kao emir Alepa od 944. protiv Bizantinaca uglavnom nizao vojne uspjehe i uspijevao braniti sirijsku granicu, čak $s$ vremena na vrijeme i vršiti gazijske upade u bizantski teritorij. Njegovo junaštvo na bojnom polju i izvan njega osiguralo mu je istaknuto mjesto u arapskoj viteškoj tradiciji, za koje su se pobrinuli pjesnici koje je ugošćivao i obilato nagrađivao. Njegov rođak Abu Firas i Mutanabbi, koji mu je posvetio čak 22 medhije (panegirika), učinili su Alep prijestolnicom arapske kulture. Za Ibn Nubata i Sejfud-Davla kao muslimane smrt je bila jedina neizbježna činjenica u životu. Vrijeme, mjesto i način susreta čovjek ne zna, ali zna da svaki njegov dah može biti posljednji. 


\section{SMrt ZA PREDislamSKOG PJESNIKA}

Poezija je duboko ukorijenjena u arapskoj tradiciji. Uz teme plemenskog neprijateljstva, invazije i pljačke, otmice žena, osvete, junaštva, viteštva i ljubavi, tema smrti bila je trajna preokupacija arapskog pjesnika, kako u predislamskom periodu tako i nakon islamske Objave. I sâm početak klasične arapske kaside promišljanje je prolaznosti i žalovanje nad minulim, tzv. nasīb. ${ }^{1}$ Kao i u drugim pjesničkim tradicijama, elegija (rițta’) je i u klasičnoj arapskoj poeziji jedan od temeljnih žanrova, možda čak i najstariji, s korijenima koji sežu duboko u predislamski period. ${ }^{2}$ Potječe iz ritmizirane proze koju su izvodile žene oplakujući članove obitelji. Fokus je pjesme pohvala preminulom zbog njegove privrženosti tradicionalnim beduinskim vrijednostima poput hrabrosti, velikodušnosti i strpljivosti, nakon koje slijedi gorko shvaćanje da je smrt neizbježna čovjekova sudbina i jedina konstanta života. Glagoli u perfektu mnogo su češći od onih u imperfektu, ${ }^{3}$ a vrijeme je linearno. Sve teče, a razvalina koju će uskoro prekriti pustinjski pijesak metafora je zemaljskog života.

Ono što je minulo i neće se vratiti obavijeno je tugom i tjera u plač. Ono čemu se čovjek koji napušta ovaj svijet jedino može nadati jest to da ga oplakuju njegovi bližnji i da ga se sjećaju buduće generacije. Pjesnik, a posebno ratnik-pjesnik, brine se o tome kako će ga pleme pamtiti kad ga više ne bude. Pjesnik Tarafa bin Al-Abd (543. - 569.) u svojoj muallaki ${ }^{4}$ tako pjeva:

Ako stradam, pjevaj o meni kako mi dolikuje, o kćeri Mabedova, i cijepaj svoju odjeću. ${ }^{5}$

Smrt je za Tarafu i velika ujednačiteljica:

Plemenit čovjek se napaja tijekom života, Kad umremo znat ćeš koji od nas još žeđa.

Vidim grob škrtice, što bdije nad imovinom

Jednak je grobu onog predanog zabavi i traćenju imetka:

Vidiš dvije humke zemlje, a na njima

Čvrste nadgrobne ploče jedna do druge. ${ }^{6}$

$\overline{1} \quad$ Nasib je nostalgično otvaranje kaside u kojoj pjesnik razmišlja o protjecanju vremena. Opće je mjesto pjesnikova potjera za karavanom njegove drage, ali kad dođe do logora, koji se obično nalazi među ruševinama, njezina je karavana već krenula dalje. Najbolji je primjer ovoga distih kojim počinje arapska poezija - početak muallake Imrul-Kajsa (501. - 565.), prvog arapskog pjesnika čiji je korpus poezije ostao sačuvan: „Stanite da plačemo sjećajući se drage i staništa / Na pješčanim dinama između Dahula i Havmala."

2 Predislamska poezija može biti prilično precizno definirana kronološki u periodu od 150 do 200 godina prije islamskog otkrivenja, što je i vremenski period koji spominje Džahiz u Kitāb al-Hayawān. Usp. Al-ğāHIž, Kitāb alHayawān (ur. 'Abd as-Salām Hārūn), sv. 1, Kairo 1965., 74.

3 Za razliku od indoeuropskih jezika, u kojima su perfekt i imperfekt prošla vremena, arapski jezik poznaje samo dva osnovna vremena (aspekta) - perfekt (al-māḍ̄ $)$ izražava svršenu, dok imperfekt (al-muḍāri') označava nesvršenu radnju (vid).

4 Muallake (arap. mn. mu'allaqāt- „ovješene“) su najljepše kaside najpoznatijih sedam (ili deset) arapskih predislamskih pjesnika. Prema predaji, kaside se bile napisane zlatnim nitima i ovješene o zidove Kabe. Zbirku je najvjerojatnije priredio Hammad ar-Ravija potkraj 8. stoljeća.

5 AḤmad al-Amīn aš-ŠAnQīțī, Šarh al-mu'allaqāt al-'ašar, Sidon - Beirut 2005., 66.

6 Isto, 61-62. 
Predislamski pjesnik personificira smrt na često vrlo poetske, a istovremeno sablasne načine. Tarafa je, ponovno u muallaki, vidi kao avet s užetom u ruci:

Tako ti života, smrt ne promaši mladića

Opušta uže koje ostaje čvrsto u njenoj ruci. ${ }^{7}$

Iz straha od smrti u predislamskog pjesnika javlja se i specifičan hedonizam. Smrt je velika uništavateljica užitka koji će jednako pogoditi i škrticu i rasipnika. Nije li onda bolje uživati u životu, pita se Tarafa?

Ti koji me zbog odlaska u bučni boj prekorijevaš,

I zbog uživanja - hoćeš li me ti ovjekovječiti?

Ako već ne možeš odagnati moju sudbinu,

Onda me bar pusti da se s njom nadmećem trošeći što imam.

Kad ne bih imao tri strasti mladića, kunem se,

Ne bih mario kada će me prijatelji posjetiti na samrtnoj postelji:

Prva je da se $s$ kritičarima nadmećem koliko ću popiti

Tamnocrvenog vina što se pjeni kad vodu uliješ;

Druga je da suosjećam kad me dozove komu je pomoć potrebna

Tad sam na konju poput vuka ispod drveta koga si prenuo dok izvor traži;

Treća je da kratim oblačan dan, strašno oblačan u nasladama

$S$ ljupkom ženom u šatoru na stupovima podignutom. ${ }^{8}$

Ipak, Tarafa ovdje čini nešto neobično. Uz tjelesni hedonizam, uvodi i moralnu dimenziju čovjekova zemaljskog postojanja. Uz vino i ženu, nedostajat će mu i pomaganje ugroženima. Islam je revolucionirao simboličnu terminologiju i principe razumijevanja poznate već predislamskim Arapima. I predislamski period poznavao je moralne vrline - junaštvo (hamāsa), plemenitost (karam) i blagost (hilm). Islam je ovoj predislamskoj formi dao sadržaj. Ove tri vrline bile su nužne za opstanak u teškim uvjetima Arabije, ali ih je islam opravdao metafizičkom doktrinom. Najviše je uzdignuta plemenitost. Kur’an objavljuje: „Najugledniji od vas (akramukum) kod Allaha je onaj koji ga se najviše boji!“ (El-Hudžurat, 13). Predislamska Arabija, iako je izgradila složen društveni sustav temeljen na istančanom shvaćanju plemenitosti, nije bila spremna ovu najvišu vrlinu dovesti u vezu sa strahom od Boga (taqwá). ${ }^{9}$ Tu revolucionarnu promjenu omogućio je islam.

Život je trajna borba u kojoj se čovjek junački nadmeće s protivnikom koji će ga na kraju ipak nadvladati:

Vidim život kao blago što se svake noći smanjuje,

A ono što dani i sudbina (dahr) smanjuju - to i nestaje. ${ }^{10}$

Ono što čovjek može jest ne dopustiti da mu protivnik oduzme slasti zemaljskog života. Ne jadikuje i ne pada u očaj. Carpe diem - svaki trenutak na ovom svijetu treba iskoristiti

\footnotetext{
Isto, 62 .

8 Isto, 60-61.

9 Toshihiko Izutsu, God and Man in the Qur'an. Semantics of the Qur'anic Weltanschauung, Kuala Lumpur 2002., 40.

10 A. A. aš-ŠANQīṬī, Šarh al-mu'allaqāt al-'ašar, 62.
} 
prije nego što bude prekasno. Gotovo da u ovim stihovima prepoznajemo Alkeja, koji pjeva: „Pijmo! Zašto da čekamo svjetiljke? Samo prst danjeg svjetla preostaje.“11

A da će svatko ispiti gorki kalež upozorava i pjesnik Umejja bin Abi Salt (7. stoljeće):

Tko ne umre kao mladić, umre kao starac

Jer smrt je kalež a čovjek kušač. ${ }^{12}$

Drugi predislamski pjesnik Lebid bin Rabi’a (560. - 661.) u svojoj elegiji za bratom Arbadom kratkoću zemaljskog života uspoređuje sa zvijezdom padalicom:

Što je čovjek doli zvijezda padalica, prolazna svjetlost

Pretvoren u pepeo nakon što zasvijetli.

Što je imetak i rodbina doli zajam.

A svaki zajam jednom mora biti vraćen. ${ }^{13}$

Ipak, koliko god život bio kratak i bremenit, za predislamskog pjesnika smrt može jednostavno biti odmor nakon dugog života. Zuhejr bin Abi Sulma (520. - 609.) u svojoj muallaki pjeva:

Umorile me životne nevolje, a tko doživi

Osamdeset godina mora da su ga umorile! $!^{14}$

Iako danas posjedujemo velik korpus predislamske poezije, jasnu predodžbu drevnog Arabljanina o onostranom nemamo (kao što, uostalom, nismo sigurni ni oko vjerske pripadnosti većine pjesnika). Ipak, Zuhejr bin Abi Sulma ovdje predstavlja iznimku. U muallaki tako savjetuje:

Nipošto ne tajite pred Bogom šta vam je u dušama,

Kako biste to sakrili, jer ma koliko tajili Bog to sazna!

Čak i ako zakasni, zapisat će kaznu u Knjizi i pohraniti ju

Za Sudnji dan, ili će pak požuriti i kaznu žurno izvršiti. ${ }^{15}$

Ovdje se pojavljuje niz motiva koje uobičajeno smatramo isključivo islamskima (Sudnji dan, knjiga, kazna), tj. slikama obračuna ${ }^{16}$ i proživljenja. ${ }^{17}$ Ibn Kutejba (828. - 889.), ko-

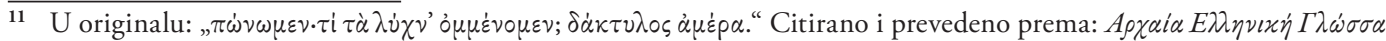

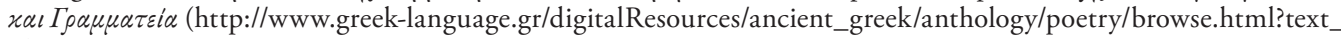
$\mathrm{id}=260$ ).

12 Umayya bin abī aș-ṢA ALt, Dīwān (ur. Samī’ Ğamīl al-Ğubaylì), Beirut 1998., 172.

13 Labīd bin Rabī'A, Dìwān (komentar Tusija), Beirut 2003., 111.

14 A. A. aš-ŠANQīị̄ī, Šarh al-mu'allaqāt al-'ašar, 87.

15 Isto, 82.

16 Obračun (arap. hisāab) je ispostavljanje računa svakomu čovjeku na Sudnjem danu za djela počinjena na ovom svijetu (dunjaluku). U trenutku obračuna svaki će se čovjek sjetiti svojih djela i kajati zbog prijestupa ili propuštenih prilika za činjenje dobrih djela (El-Fedžr, 23-24; El-Kehf, 48). Svakomu će biti podijeljena knjiga; onaj komu bude podijeljena u desnu ruku bit će spašen i nagrađen (El-Hakka, 19-20), a komu bude dana u lijevu bit će osuđen i kažnjen (El-Hakka, 25-29). Bit će postavljena i vaga (mĩzān) na kojoj će se pravedno vagati ovozemaljska djela svakoga čovjeka (El-Anbija, 47; El-Araf, 8-9), a posljednje je iskušenje most (șirāṭ̂), oštriji od sablje i tanji od kose, postavljen iznad džehenema (pakla), preko kojega će ljudi prelaziti do dženeta (raja). Prvi će preko mosta prijeći Muhamed a. s., a potom njegov ummet (Merjem, 71-72).

17 Proživljenje (arap. $b a^{\prime} \underline{t}$ ) je sjedinjenje duše s tijelom pred Sudnji dan. Prema Ku'ranu (En-Naml, 87-90), nakon drugoga puhanja u rog (pri prvom puhanju sve što živi umrijet će) Allah dž. š. oživjet će mrtve iz njihovih grobova i 


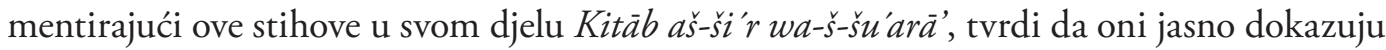
kako je Zuhejr vjerovao u proživljenje. ${ }^{18}$

Ka’b bin Zuhejr (7. stoljeće) u svojoj poznatoj kasidi Bānat Su'äd, nazvanoj tako prema prvim dvjema riječima „Otišla je Su’ad“, donosi sliku žena koje oplakuju smrt svoje djece: ${ }^{19}$

Sin svake žene, pa i ako uživa u dugoj sigurnosti

jednog dana će na zakrivljenim nosilima biti nošen. ${ }^{20}$

Svaki poznavatelj Homera ne može, čitajući ove stihove, ne prisjetiti se slike Ahilejeva oplakivanja mrtvog Patrokla iz 23. pjevanja Ilijade (222-225). ${ }^{21} \mathrm{Na}$ metaforičkoj razini, kao da je ova slika posljednji hommage predislamskom svijetu temeljenom na ratničkom etosu i plemenskoj solidarnosti. Svijetu koji je morao umrijeti kako bi se novi, onaj islamski, temeljen na odbacivanju plemenskih veza i zastarjelih tradicija, mogao roditi.

\section{ISLAM I SMRT}

Ka’b bin Zuhejr, koji je nakon duljeg odbijanja prihvatio islam, predstavlja trijumf islamskog monoteizma. Dvadeset i tri godine Muhamedova a. s. poslanstva donijele su nov pogled na život i smrt, ovozemaljsko i onostrano. Kako islam gleda na smrt? Kur’an, za muslimane posljednja Božja objava, upozorava da će sve što živi jednom umrijeti. „Sve što je na Zemlji prolazno je!“ (Er-Rahman, 26) i „Svako živo biće smrt će okusiti!“ (kur’anska fraza spomenuta čak tri puta - Alu Imran, 185; El-Enbija, 35; El-Ankabut, 57). Čas i mjesto smrti čovjek ne može znati (Lukman, 34), ali jednom kad dođe, „ni za tren ga jedan ne mogu ni odgoditi ni ubrzati“ (En-Nahl, 61). Svaki čovjek treba dobro paziti da dobra djela čini u pravom trenutku, prije nego što bude prekasno: „I od onoga čime vas Mi opskrbljujemo udjeljujte prije nego nekom od vas smrt dođe, pa da onda rekne: 'Gospodaru moj, da me još samo kratko vrijeme zadržiš, pa da milostinju udjeljujem i da dobar budem!' Allah, sigurno, neće ostaviti u životu nikoga kome smrtni čas njegov dođe; a Allah dobro zna ono što vi radite." (El-Munafikun, 10-11). Svakako je jedna od najpoetskijih slika smrti ona o otimanju duše. Arapski glagol tawaffá (spomenut u El-An’am, 60; Es-Sedžda, 11;

povratiti im duše u tijela u stanju u kojem su umrli (Jasin, 51-54; El-Muminun, 15-16) te ih okupiti (hašr r) na Sudnji dan, na kojem će svaki čovjek odgovarati za djela počinjena na ovom svijetu. U hadisima koje prenosi Abu Hurejra, a bilježe Buhari i Muslim (Muslim 2955; Buhari 1836), Muhamed a. s. spominje da će sve ljudske kosti istrunuti, osim repne kosti (adžbuz-zeneb), iz koje će pri proživljenju izrasti čitav čovjek; prvi će se otvoriti Muhamedov grob, a on će se na Sudnjem danu založiti za spasenje drugih.

18 Ibn Qutayba, Kitāb aš-ši'r wa-š-šu'arā' (ur. AḤmad MuHammad Šākir), Kairo 2006., 139.

19 Ka’b (sin Zuhejra bin Abi Sulme) bio je među najcjenjenijim pjesnicima kasnog džahilijeta. Kad je do njega stigao glas o Muhamedovu a. s. pozivanju ljudi u islam, on i njegov brat Budžejr otišli su do Muhameda, ali je Ka’b promijenio mišljenje i vratio se. Budžejr je, pak, prihvatio islam. Kada je Ka’b otkrio da je njegov brat postao musliman, napisao je satiričnu pjesmu. Ipak, nedugo se kasnije pokajao, prihvatio islam i pred Muhamedom izrekao ovu kasidu. Muhamed ga je tada ogrnuo svojim plaštem (burda). Ka'b bin Zuhayr, Dìwān (ur. 'Alì Fā'ūr), Beirut 1997., 65.

21 „Kao što rida otac, kad kosti mladoženje sina / Pali, koji je smrću rastužio jadnoga oca / I mater: tako je rido Ahilej drugarove kosti / Paleć, uz lomaču pužuć i uzdišuć tužno za njime." Citirano prema: Homer, Ilijada (preveo i protumačio Tomo Maretić), https://edoc.site/homer-ilijada-pdf-free.html, 369. 
Ez-Zumar, 42) znači „ugrabiti“, „dokopati se u potpunosti“, tj. u pasivu „biti ugrabljen“, „umrijeti“. Onaj koji grabi jest sâm anđeo smrti (malak al-mawt, spomenut u Es-Sedžda, 11 i poznat u islamskoj tradiciji kao Azrail, iako to ime nije potvrđeno ni Kur'anom ni vjerodostojnim hadisima). Ono što je ugrabljeno jest čovjekova duša koju anđeo u trenutku smrti izvlači iz zatočeništva prolaznog tijela. Od trenutka smrti do Sudnjeg dana i proživljenja, duša boravi u prostoru zvanom berzah (arap. barzah - „prepreka“), gdje uviđa posljedice ovozemaljskih djela. Nakon što svi ljudi budu proživljeni (El-Vakija, 49-50; Merjem, 93-95; El-Kehf, 47-49), bit će okupljeni (arap. hărrr) na jednom mjestu (mahšrer), u strahu i neizvjesnosti, kako bi obračun mogao započeti. Dinamičan način na koji islam opisuje Sudnji dan djelovao je na Arape tako da vjeruju u onostrano, raj i pakao te u apsolutnu pravdu Stvoritelja. Opreka ovozemaljskog i onozemaljskog sada postaje potpuna: „A na onome svijetu je teška patnja i Allahov oprost i zadovoljstvo; život na ovome svijetu je tek varljivo naslađivanje!“ (El-Hadid, 20). U shvaćanju prolaznosti ovozemaljskog života nema velike razlike između predislamskog i islamskog pogleda. No, njihovi su zaključci suprotni. Dok je predislamski Arapin bio ograničen trenutačnim postojanjem, islam je onostrano učinio na temelju vjere. ${ }^{22}$ Čovjek više nema potrebe očajavati. Ideja besmrtnosti (hulūd), koja je predstavljala nerješiv problem ranijim pjesnicima, sad je dostižna, s one strane obzora postojanja - „Ali, vi više život na ovom svijetu volite, a onaj svijet je bolji i vječan je!“ (El-A’la, 16-17).

Sveobuhvatnost promjene koja je nastupila islamom vidljiva je i u arapskom jeziku. Zanimljivo je da 76. sura Kur’ana ima dva imena: El-Insan (Čovjek) i Ed-Dahr (Vrijeme). Dahr u Kur’anu više nema značenje sudbine, tj. samrtnog časa (sinonim riječi maniya) kakvo ima u predislamskoj poeziji i čije semantičko polje kasnije u arapskom jeziku preuzima riječ qadar. Dahr sad dobiva novo značenje, postaje vrijeme i gubi svoju svemoć. Dok predislamski dahr određuje tijek i kraj čovjekova života, iznad islamskog dahra stoji Allah dž. š.: „Samo Allah je zapisao sudbinu svih stvorenja pedeset hiljada godina prije stvaranja nebesa i Zemlje, dok je Arš (Allahovo prijestolje - op. E. M.) bio na vodi.“' (Muslim, 1841).

Osim Kur'ana, brojni vjerodostojni hadisi opominju vjernike da na ovaj svijet gledaju kao na prolazno boravište. U jednom koji donosi Buhari navodi se: „Uhvatio me je Allahov Poslanik za rame i rekao: 'Budi na ovome svijetu kao da si stranac ili putnik!'“ (Buhari, 6416).

U drugom, također iz Buharijeve zbirke: „Vjerovjesnik je nacrtao kvadrat i povukao jednu liniju kroz sredinu, koja je izlazila iz njega. Zatim je nacrtao manje linije sa strane okrenute prema liniji u sredini i rekao: 'Ovo je čovjek, a ovo je njegova smrt (ağal), koja ga okružuje. Ova linija koja je izvan - to je njegova nada, a ove male linije jesu nevolje koje ga prate $\left(a^{\prime} r \bar{a} d\right)$. Ako ga jedna promaši, pogodi ga druga; ako ga promaši druga, pogodi ga prva." (Buhari, 6417).

22 Toshihiko Izutsu, Ethico-Religious Concepts in the Qur'ān, Montreal - Kingston 2002., 50. 


\section{SMrt Za islamskog PJESNika}

Mutanabbi (915. - 965.) je najveći arapski pjesnik i najekspresivniji medij arapskog pjesničkog genija. Sin je vodonoše iz drevnog jemenskog plemena; rano prepoznat pjesnički talent izbavio ga je teška života osiguravši mu dobro obrazovanje. Kad su ismailitski Karmati 924. godine zauzeli Kufu, pridružio im se i 932. čak stao na čelo karmatske revolucije u Siriji. Nakon poraza pobunjenika i dvogodišnjeg tamnovanja, pokajao se 935. godine i postao lutajući pjesnik. Njegove medhije postale su tako slavne da ga je Sejfud-Davla doveo 948. na svoj dvor. Na alepskom dvoru ostao je devet godina, prateći svog patrona u svim pohodima. Smrt je tijekom tih godina dobro upoznao. U jednoj poznatoj kasidi veliča junačku smrt:

Prkosno živi ili časno pogini

Između britkih oštrica i barjaka što lepršaju!

Junačka smrt više nije besmislena smrt u plemenskim obračunima predislamskih Arapa. Ona je sad smrt gazijskog ratnika koji brani granice islama. Smrt koju će ratnik željeti ponovno proživjeti: „Zaista su duše šehida u utrobama zelenih ptica, lete po dženetu (raju) kuda žele. A potom se sklanjaju u kandilje okačene ispod Arša. Njihov Gospodar im se javlja i pita ih: ‘Što želite?', a oni odgovaraju: 'Gospodaru nas! Što još možemo poželjeti kada si nam dao što nikome od Svojih stvorenja nisi dao?' On ih nastavlja pitati sve dok ne shvate da neće biti ostavljeni bez odgovora pa rekoše: 'Želimo da nas vratiš na Zemlju da se borimo na Tvome putu kako bi ponovo, u Tvoje ime, poginuli'“ (Muslim, 1887). Ipak, savjetuje nas Mutanabbi ljudski, ne treba žuriti u smrt. Nisu li najveći pjesnici - Arhiloh, Alkej, Anakreont ili Horacije - u žaru bitke izabrali život i bacili štit:
Ako se izlažeš opasnosti tražeći čast
I ništa manje od zvijezda ti ne donosi zadovoljstvo
(Znaj da) je okus smrti pri maloj
Poput onoga pri velikoj stvari. ${ }^{23}$

Poput Zuhejra, i Mutanabbi u smrti vidi bijeg od životnih problema:

Nevoljko oplakujemo naše mrtve,

jer znamo da samo taštinu ostavljaju za sobom

Ako razmisliš o nevoljama života,

shvatit ćeš da je bolje od ruke neprijatelja stradati. ${ }^{24}$

Brzina kojom anđeo smrti napada plaši ga, a najpotresniju sliku pronalazimo u njegovoj elegiji prilikom smrti majke Sejfud-Davla:

Pripremamo mačeve i koplja, a smrt nas pobije bez borbe; 
Privezujemo brze konje pored šatora, ali od kasa noći nas ne izbave! ${ }^{25}$

Konfrontacijom dvaju distiha Mutanabbi, otkrivajući duboku razliku u moći, prikazuje paradoks smrti. Dok bi vokabular prvog distiha (mačevi, koplja, konji) mogao poslužiti u medhiji Sejfud-Davla, koji je gospodar života i smrti na bojnom polju, drugi jasno pokazuje nemoć ratnika koji se usude smrti stati na megdan. Mutanabbi se koristi vokabularom medhije, a ulogu ratnika preuzima smrt, koja je ovdje, kao i u srednjovjekovnoj kršćanskoj imaginaciji, personificirana kao konjanik koji jaše konja u kasu, mač ga ne siječe, a koplje ne probada. Sejfud-Davla, koji se na konjskom sedlu bezbroj puta suočio $s$ neprijateljem, ovog puta ne može pobijediti i spriječiti majčinu otmicu. ${ }^{26}$ Borba sa smrću jest agon, egzistencijalan i herojski, ali protivnik ne igra pošteno. Smrt je perfidna i bez milosti. Ipak, ovdje je, koliko god na prvi pogled neuočljiv, vidljiv jasan islamski svjetonazor. Mutanabbijeva elegija više nema mnogo toga zajedničkog s predislamskom. On kao da izaziva smrt: „Dođi! Uzmi me, ne hajem, jer znam da ću pobijediti!“ Elegija više nije plač ožalošćenog, ona je koplje pobunjenika upereno prema smrti:

O Sejfud-Davla, traži pomoć u snazi,

Jer kako bi planine ikad mogle biti ravne tvojoj snazi?

Učiš narod kako da strpljivo podnosi breme

I na smrt navali u nepredvidljivom ratu.

Mijene vremena s kojima se suočavaš su brojne,

Ali na tvoje stanje mijene ne utječu! ${ }^{27}$

\section{ZAKLJUČAK}

Smrt je jedan od najzastupljenijih i, kako svjedoči ep o Gilgamešu, najstarijih motiva u poeziji. Predislamski arapski pjesnik kao da je vidi posvuda oko sebe - lešine životinja pored karavanskog puta, ruševine gradova koje je prekrio pijesak. Smrt je nemilosrdna i pravedna, nije ju moguće prevariti, niti spoznati njezinu tajnu. Ipak, u predislamskog pjesnika smrt ne pobuđuje razmišljanje o onome što se nalazi s one strane. Ona svakako pobuđuje ovozemaljske brige, ali one koje izviru iz svijesti o gubitku, a ne iz straha od kazne ili truda oko nagrade. Vizija je smrti pesimistična, beznadna, čak i ako gorak ovozemaljski život nije vrijedan življenja. Moglo bi se reći i da je krik očaja nad prazninom života konstanta predislamske poezije. Islam će sve promijeniti. Čovjeku daje smisao života i objašnjava da je smrt zakon neodvojiv od života, njegovo drugo lice. Iako je i dalje neminovna i bolna za bližnje, pravednik se sad ima čemu nadati. Za čestit život bit će nagrađen, a najveća je nagrada gledanje u Allahovo lice (El-Kijama, 22-23). Smrt je tek odvajanje duše od tijela i kidanje veze koja će se ponovno uspostaviti pri proživljenju. U besmrtnost duše vjerovali su još drevni Egipćani, a aspekt duše koji u trenutku smrti

\footnotetext{
$25 \quad$ Isto, 265.

26 Margaret Larkin, Al-Mutanabbi. Voice of the Abbasid Poetic Ideal, Oxford 2007., 45.

27 Al-Mutanabīi, Dìwān, 268.
} 
napušta tijelo (Bâ) prikazivali su hijeroglifom ptice s pokojnikovom glavom, dok je sli-

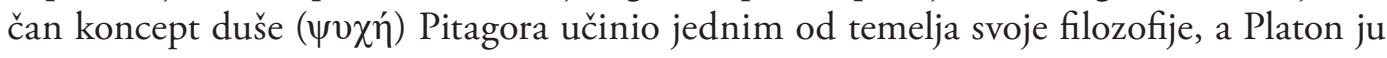
je detaljno izložio u Fedonu. I u islamu sama esencija duše, koja čini i esenciju čovjekova bića, ostaje kakva je i bila. Smrt je samo prijelaz. Kako je rekao pobožni kalif Umar bin Abdul-Aziz: „Vi ste stvoreni za vječnost (abad) i samo se premještate iz jednog boravišta u drugo (min dār ilá dār)!“

\section{$\cos$}

\section{Literatura}

AL-Ğ̄̄èz, Kitāb al-Hayawān (ur. 'Abd as-Salām Hārūn), sv. 1, Kairo 1965.

Al-Mutanabī̄, Dìwān, Beirut 1983.

Homer, Ilijada (preveo i protumačio Tomo Maretić), https://edoc.site/homer-ilijada-pdf-free.html. Toshihiko Izutsu, Ethico-Religious Concepts in the Qur'än, Montreal - Kingston 2002.

Toshihiko Izutsu, God and Man in the Qur'an. Semantics of the Qur'anic Weltanschaunng, Kuala Lumpur 2002.

Margaret Larkin, Al-Mutanabbi. Voice of the Abbasid Poetic Ideal, Oxford 2007.

Ibn Qutayba, Kitāb ašššì'r wa-šs-šsu'arā’’ (ur. AḦmad MuHammad Šākir), Kairo 2006.

Labīd bin Rabī́A, Dìwān (komentar Tusija), Beirut 2003.

Umayya bin abī aṣ-ȘALt, Dìwān (ur. Samī' Ğamìl al-Ǧubaylī), Beirut 1998.

AḤmad al-Amīn aš-ŠANQīṭī, Šarh al-mu'allaqāt al-'ašar, Sidon - Beirut 2005.

Ka'b bin Zuhayr, Dìwān (ur. 'Alī Fā'ūr), Beirut 1997.

\section{Mrežna stranica}

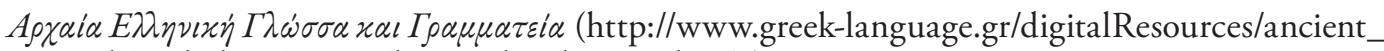
greek/anthology/poetry/browse.html?text_id=260). 


\section{$\cos$}

\section{“DEATH IS A CHALICE AND MAN IS THE TASTER": DEATH IN EARLY ARABIC POETRY}

Human beings are troubled by death from the moment they become self-aware. Biology, philosophy and religion all try to get to the heart of the mystery of death in their own ways. In this sense, the purpose of poetry is to comfort the mortal, and Arabic poetry is no exception, with the elegy as its perhaps oldest genre. The author examines the attitudes towards death expressed by pre-Islamic poets, as well as the shift in Arabic poetry that occurred with the emergence of the new cultural universe of Islam. In the works of pre-Islamic poets, death seems to be in perfect accordance with the harsh and unforgiving desert environment: a terrifying wraith which snatches without mercy. Since a mortal can expect no mercy at the end of his days, every moment before death must be lived to the fullest. In the works of certain poets, such as Tarafa, this sort of hedonism takes on a moral dimension. For Tarafa, a life well-lived is one that ends with no regrets for missed opportunities to do good. A moral revolution already heralded by Zuhayr bin Abi Sulma and brought about by Islam created a new world. A Muslim no longer doubts the existence of the afterlife. Instead, death is regarded as but a transition to the other side, where the soul is awaited either by the anticipates or the punishment it dreads. In any case, death is no longer inevitably perceived as the bitter end. This becomes most evident in the poetry of the greatest Arab poet, Mutanabbi, who, in his works, challenges death after the loss of loved ones, and emerges triumphant.

Key words: Islam, death, pre-Islamic poetry, muallake, Mutanabbi 